\title{
Problematizando o Conceito de Desenvolvimento: povoando as interfaces
}

\author{
Arguing the Development Concept: Populating the interfaces \\ Professor Mestre (Psicossociologia de Comunidades e Ecologia Social - UFRJ) \\ Júlio Cesar de Almeida Nobre - \\ jcanobre@globo.com
}

\begin{abstract}
Resumo
O presente trabalho tem por objetivo realizar uma reflexão acerca do conceito de desenvolvimento, explorando uma concepção diferenciada da moderna oposição entre saberes locais e saberes globais a partir de uma discussão acerca da produção de saberes na atualidade. Pensamos ser bastante fértil problematizarmos tal concepção binária já clássica do termo, por intermédio do modelo de redes do sociólogo das ciências Bruno Latour. Em tal modelo, toda concepção de globalidade se constitui em mediações sempre locais. Concluímos que, dessa forma, o foco do desenvolvimento recai sobre as diversas amarrações entre os diferentes atores envolvidos nas tramas e interfaces das redes. Desenvolvimento, dessa forma, pode ser entendido como uma interação entre diferentes, uma constante mediação/hibridação entre diferentes.
\end{abstract}

Palavras-chave: Redes; Desenvolvimento; Saber global; Saber local.

\section{Abstract}

The present work objectifies a study concerning the development concept, exploring a conception differentiated from the modern opposition of local knowledges and global knowledges starting from a discussion concerning the knowledges production at the present time. We think to be very fertile argue such classical binary conception of the term, through the sociologist nets model of the sciences Bruno Latour. In such model, all conception of universal 
constitutes in mediations always locations. We conclude that, thus, the development focus relapses in the different actors several articulations involved in the nets woofs and interfaces. Development, thus, can be understood as a constant mediation / different agents hybridization.

Words-key: Nets; Development; Global Knowledge; Local Knowledge.

\section{Introdução}

O movimento moderno surge, a partir de meados do século XVII, com uma perspectiva dicotômica entre natureza e cultura, entre o mundo dos humanos e dos não-humanos. De um lado a fluência "viva" da cultura, dos humanos e, do outro, de modo estanque, o mundo atemporal das Verdades imutáveis da natureza. O moderno, através de seu método científico, se via como dotado de um “dom especial” que o permitia alcançar esse mundo atemporal e assim obter o universal, aquilo que realmente é. Essa visão dicotômica cria, segundo Milton Santos (2000), um abismo entre a dimensão política e a dimensão técnica que, em diferentes momentos, diferentes situações, canalizam as interpretações acerca do mundo. O que se vê são imagens duplicadas, um discurso dividido, cindido. De um lado aquilo que é da ordem do "puro" conhecimento, da técnica; de outro, aquilo que é da ordem do político, do poder, das relações humanas. Essa separação entre o conhecimento e a política se traduz em uma despolitização do próprio conhecimento, que acaba por impedir que este possa pensar sua própria construção. Os modernos, ao verem o conhecimento desamarrado da política, das relações humanas, isto é, um conhecimento das "coisas de fato”, transformam diferenças em oposições entre verdadeiro e falso, entre "as luzes e a escuridão”, criando um campo de discussões simplista entre o saber legítimo e o ilegítimo.

Segundo Morin (1995), atrelado à noção de uma tecnociência que garantiria esse percurso rumo a uma pura positividade, encontrava-se o conceito de desenvolvimento. Este deveria propiciar o progresso, isto é, a Modernidade ocidental científica, técnica e industrial, avalizada pelo crescimento econômico. Ser desenvolvido, em outras palavras, era simplesmente o mesmo que ser rico, industrializado e fundamentado na tecnociência ocidental moderna. Nesse sentido, o subdesenvolvido seria o "eles" do desenvolvido, o que ainda está aquém daquilo que um “desenvolvido” já é. Este subdesenvolvido, marcado pela falta, deveria então tudo sacrificar no intuito de alcançar o tão desejado crescimento econômico, industrial e técnico. O modelo de desenvolvimento, o mapa que indicaria o caminho para a “vitória”, estava disponível.

Alguns estudiosos contemporâneos, pensando em uma outra direção onde a política e o conhecimento seriam dimensões do mesmo, oxigenam a discussão acerca do conceito de desenvolvimento, conceito esse que, estando atrelado à noção de ciência, sofre um importante abalo com a crise enfrentada por esta no decorrer do séc. XX. Nesse período, o conhecimento científico e técnico, lugar dos universais, do saber que vale para tudo e para todos, tem seu status de pureza contestado. Essa contestação surge quando seu mais sólido 
e central fundamento se apresenta falho: a crença em um progresso inevitável rumo a uma bem aventurança final, desde que o caminho fosse ditado pela ciência e pela técnica, rompendo, assim, com todos os erros e faltas passados que deveriam ser superados um a um durante este percurso. A ciência, assim como a indústria - todas elas criações da Modernidade - deixam de ser a garantia de um futuro melhor como até então haviam sido. As estatísticas, no decorrer do século XX, mostram índices sempre crescentes de pobreza, desigualdades sociais, degradação do ambiente, etc, que apontavam para a falácia do progresso garantido, “financiado” pela ordem científica.

Com a falência desse conceito clássico de desenvolvimento, surge todo um ambiente de discussão sobre novos caminhos a seguir. Penso que, como pré-requisito para entrarmos nesse ambiente, faz-se urgente um entendimento dos fundamentos daquilo a que chamamos conhecimento, visto que o conceito de desenvolvimento há muito segue atrelado à noção de ciência - até então detentora exclusiva da "patente" da Verdade - e entra em crise a partir da própria crise dos fundamentos científicos.

\section{O Saber Global: uma rede em expansão}

A ciência ocidental moderna surge, em meados do séc. XVII, conjuntamente com a criação de uma dicotomia entre a natureza e a cultura. Segundo Prigogine (1991), o conhecimento legítimo, aquele que é em si, ficou associado às ciências naturais, que viam a natureza como um mundo exterior ao observador humano e disponível à sua manipulação, desde que devidamente abordada pelo método científico, o qual garantiria a posse - por parte dos humanos - das leis que a regem. Com esse formato clássico, a ciência adquiriu um enorme prestígio e legitimidade que, em contrapartida, esvaziou a validade de todas as outras formas de conhecimento, como se estas estivessem superadas pela eficácia do método científico. A ciência caminhou, desde então, sem grandes abalos nos seus fundamentos até que, no final do séc. XIX, enormes problemas surgiram, no interior das ciências físicas, que não puderam ser resolvidos a partir de suas próprias premissas. Surgiriam enormes paradoxos que, para serem assimilados, demandaram uma alteração das próprias bases das ciências físicas, bases essas que serviam de modelo para as outras ciências ocidentais e lhe conferiam prestígio e legitimidade incontestes. É no pensamento de Thomas Kuhn (2000), físico e historiador da ciência, que a condição de exclusividade dada ao conhecimento científico daquilo que é Verdadeiro é mais fortemente atacado. A ciência passa a ser reconhecida como um processo de solução de problemas ditados por um paradigma, que limita suas formulações, bem como suas soluções, visto que os paradigmas são

"realizações científicas universalmente reconhecidas que, durante algum tempo, fornecem problemas e soluções modelares para uma comunidade de praticantes de uma ciência” (Kuhn, 2000: 13). 
O saber científico nada mais faz do que ampliar o seu alcance dentro dos limites préestabelecidos pelo paradigma. Todo trabalho científico acontece atrelado a uma cultura, uma comunidade que tem como limite e fundamento, seu paradigma. A ciência deixa de ser divinizada e expõe seu caráter de conhecimento construído, parcial, limitado e enraizado em uma cultura como tantos outros conhecimentos. Nada mais garante sua exclusividade perante as outras formas de saber.

Ao adotarmos essa perspectiva, podemos perceber que a natureza, em contraposição ao que era postulado pela Ciência Moderna, já não mais se separa radicalmente da cultura. Aquilo a que chamamos ciência nada mais é do que uma criação cultural local, isto é, um conhecimento que brota das relações humanas, da política, e por isso enraizado em uma comunidade. Este conhecimento local se quer universal e, nesse intuito, se expandiu a tal ponto que se confundiu, realmente, com algo global. Segundo Latour (1994), essa expansão se inicia ainda nos laboratórios, quando o cientista "purifica" o experimento de tudo aquilo que diz respeito a suas condições locais, considerado como variáveis que interferem na "língua da natureza". O método científico visa excluir todo o contexto, todas as particularidades do local em que se realizou o experimento para que, somente então, possa extrair desse evento as tão desejadas leis não locais - ou globais, como desejar. O próprio movimento de exclusão de toda a ambientação do evento, transformando-o em uma observação "inodora", é a "vida" científica. A natureza que a ciência reivindica abarcar é um artifício fabricado em um local: o laboratório. A natureza "fala" através do discurso fabricado no laboratório, o que aponta para a inexistência de uma pureza, uma verdade dos objetos. Essa natureza/cultura construída - vista pela ciência como sendo natureza em estado puro - é então, “exportada” dos laboratórios, isto é, de seus locais de origem, para diversos outros locais, ocasionando uma mudança de todo o novo sistema em que ela adentra. Ela transporta, para as novas localidades, as condições do laboratório, pois somente dentro dessas condições originais de suposta pureza é que ela poderá funcionar de modo eficaz. A ciência, ao se espalhar por diversas localidades, reconstrói o mundo à sua imagem e semelhança.

Esse movimento em muito se parece ao que Milton Santos se refere no que diz respeito a entrada de grandes empresas em diversas localidades. Segundo o autor,

"quando uma grande empresa se instala, chega com suas normas, quase todas extremamente rígidas. Como essas normas rígidas são associadas ao uso considerado adequado das técnicas correspondentes, o mundo das normas se adensa porque as técnicas em si mesmas também são normas. Pelo fato de que as técnicas atuais são solidárias, quando uma se impõe, cria-se a necessidade de trazer outras, sem as quais aquela não funciona bem. Cada técnica propõe uma maneira particular de comportamento, envolve suas próprias regulamentações e, por conseguinte, traz para os lugares novas formas de relacionamento. O mesmo se 
dá com a empresa. É assim que também se alteram as relações sociais dentro da comunidade” (Milton Santos, 2000: 68).

A ciência, assim como as empresas, ao recriar em outros locais as suas condições de origem - o laboratório -, desaloja culturas cujos nativos, em função dessas mudanças, já não podem mais se reconhecer enquanto tal. Elas trazem consigo, além da encantadora proposta desenvolvimentista clássica de um futuro brilhante, um estrondoso processo de desestruturação dos locais. Os portadores das "boas novas” - cientistas, industriais, etc passam a falar pelos nativos dos respectivos locais, que se unem a eles em uma rede de trabalho. Os humanos e não humanos são nos diversos locais, assim como em um laboratório científico, ordenados de forma a reproduzir o padrão estipulado pelo modelo ordenador. O que vemos é uma relação de poder/saber (Foucault, 1999) que vai se amplificando gradativamente, uma rede de trabalho que se estende por inúmeros locais diferentes. Saber e poder, dessa forma, estão intimamente amarrados em uma rede de trabalho. Não existe um conhecimento que não esteja enraizado em relações sociais, da mesma forma que não existe social desprovido de um saber que nele brote. O que se vê é uma rede (Latour, 1994), uma “amarração” que se expande - ou na - ao englobar - ou não - novos atores - humanos ou não. Política e conhecimento se fundem.

A rede ocidental moderna se fortalece ao tentar excluir toda a multiplicidade - devido a sua concepção da totalidade do mundo como saber (global) e não-saber (local) - e expandir sua associação particular de natureza e cultura por diversos exemplos, diversas ramificações, através da falácia do desenvolvimento clássico. Essa rede busca se expandir como uma grande massa uniforme de purificação, visando decantar o impuro, o “essencialmente local”, do puro, do saber global. Entretanto, essa expansão se dá, exatamente, a partir de traduções, hibridações, associações do puro com o impuro, do local com o local suposto global. Dessa forma, a rede construída vai se naturalizando, se expandindo e se cristalizando. Porém, a manutenção dessa rede, dessa tentativa de unificação da multiplicidade em uma articulação entre humano e não humano que se quer única, depende do sucesso dessa mesma articulação. Ela precisa se manter eficaz para que se mantenha bem amarrada, pois apesar da ordem estabelecida ter se obscurecido no formato de uma pura natureza, ela não abarca a totalidade das coisas e, por isso, irá se deparar com situações que lhe escapam. Nenhuma ordem, por mais que se apresente como natural, pode conter em si mesma a totalidade das coisas, ser um detentor do universal. O "resto do mundo" é sempre deixado de fora e, a revelia do poder ordenador, "sopra” instabilidade em tudo aquilo que se apresenta cristalizado.

Não existem certezas eternas, nada simplesmente é. Aquilo que aparentemente é, é uma construção, uma rede de natureza e cultura, de não humano e humano que se apresenta como atemporal. As amarras entre natureza e cultura, quando cristalizadas, se obscurecem e surge uma dicotomia entre ambas, como se fosse uma articulação natural. O “verdadeiro” conhecimento dos fatos objetivos passa a se identificar com o pólo da natureza enquanto 
que a política, o mundo das relações humanas, é colocada no pólo oposto. O conhecimento, para ser alcançado, deve passar por todo um processo de decantação das impurezas, isto é, uma separação entre os dois pólos, entre subjetividade e objetividade, que resultaria nas Verdades objetivas da natureza. Dessa forma, o que se viu no ocidente moderno foi um humano completamente isolado do mundo dos não humanos, um homem separado de seu ambiente, da natureza.

A partir dessa visão dicotômica da natureza e da cultura, o ocidente, ao se conceber como possuidor de uma excelência, visto que seria o único a separar natureza de cultura através de seu método científico e, assim, alcançar a Verdade - situada na natureza negligencia todas as outras culturas como não possuidoras das chaves do universal. A noção de desenvolvimento apontaria, nessa situação, para um percurso entre "o Céu e a terra”, a plenitude e a falha, onde o "herói” que o trilharia rumo a redenção, esse "Cristo salvador moderno" que indicaria o "caminho das pedras", seria a ciência ocidental moderna. Dessa forma, a rede ocidental moderna, ao se expandir, negligencia que as outras naturezas/culturas são - assim como o próprio ocidente moderno - uma rede trançada entre humanos e não-humanos - incluindo aqui o que chamamos meio-ambiente. O que se vê então é um movimento cego, uma constante desorganização estrutural das redes locais que, através de suas histórias particulares, se constituíram em uma interação natureza/cultura particular. Estas passam a ser vistas como falhas, fora do saber correto, isto é, da rede ocidental moderna.

\section{A Reificação do Saber Local}

O ocidente moderno, ao ser cego para os híbridos de natureza e cultura, negligencia as diferenças como meros erros que devem ser alçados na direção do "desenvolvimento", desestruturando a relação entre as naturezas e culturas locais, os saberes locais. A rede ocidental moderna, para se naturalizar solidificando suas crenças, precisou se expandir por diversos exemplos, diversas bocas e ouvidos. Segundo Latour (1999), um fato é, antes de tudo, um enunciado que passa de boca em boca, de ouvido em ouvido e, nesse trajeto, vai se solidificando. Ele, portanto, será sempre coletivo, da ordem das relações humanas, brotará no e do local. A rede se expande, exatamente, ao converter humanos e não humanos. Todos então, passariam a seguir sua cartilha - cada um à sua maneira. Toda localidade convertida é transformada, se desestrutura. Em reação a essa desestruturação do saber local por parte do saber ocidental moderno, global, vê-se muitas vezes uma reificação do conhecimento local como se este fosse o conhecimento certo, exato, harmonioso. Dessa forma, esse conhecimento seria considerado “intocável”, seria legitimado e protegido de corpos estranhos ocidentais modernos, simplesmente por ser um conhecimento enraizado. O saber local passa a ser sinônimo de saber correto, por ser um saber considerado "vivo”,

que "brota” das relações humanas - em contraposição a um saber abstrato, invasor e inimigo. 
Parece-me que podemos entender alguns modelos contemporâneos de desenvolvimento situados dentro dessa perspectiva. Esses modelos que combatem a degradação da cultura local são, ainda, construídos a partir de dicotomias entre natureza e cultura, visto que seria necessária a postulação de uma fronteira sólida cujo interior estaria sendo depredado e alterado em seu fundamento pelo invasor. Localidade de um lado pequenas Verdades - e global do outro - grande Mentira. Se, na perspectiva do desenvolvimento clássico, parte-se de um pressuposto cego, naturalizado, de que o saber ocidental moderno é essencialmente "o Bem" e deve "catequizar" o restante do mundo, nesses modelos mais recentes de desenvolvimento, “o Bem” muda de lugar. Demoniza-se o saber global, emancipando o saber local através de uma oposição que o conduz para algo além da simples visibilidade: para o lugar do legítimo. A solução do "problema” passaria, então, a estar na preservação das culturas locais perante a global, sendo o "desenvolvimento correto", aquele que surge do "essencialmente" enraizado nas fronteiras do lugar - e, por isso, considerado legítimo. A diferença passa a ser inimiga.

Chegamos às portas do xenofobismo. Vemos culturas sendo isoladas para serem preservadas. Elas se tornam verdadeiros sólidos, incomunicáveis entre si. Cada uma delas portadora de sua identidade essencial e defendida com afinco dos estranhos. Se a cultura passa a ser a chave para o "verdadeiro" desenvolvimento, esta deve ser isolada das impurezas "externas" para que se revele um "correto caminhar". As lentes continuam dicotômicas. O conhecimento continua não conseguindo se pensar. O observador continua a se "sentar no trono da Verdade" e se querer total. O desenvolvimento passa a ser, nesta perspectiva, um processo intervencionista que visa "facilitar" os nativos a encontrarem o seu "próprio passo".

\section{Conclusão}

Passos legítimos ou ilegítimos, idéias próprias ou fora de lugar... Ora, a partir do momento em que passamos a perceber que não existem conhecimentos puros, que todo o saber é politizado e toda política "respira" saber, a dicotomia entre saber global e saber local perde o sentido. Todo e qualquer saber passa a ser enraizado em uma rede de natureza/cultura devendo ser visto enquanto tal. Não existe um saber transcendental. Tudo é interessado, parcial, local e nunca abstrato, total, global. Torna-se improdutiva, dessa forma, qualquer discussão sobre a legitimidade ou ilegitimidade de um saber. Todos são legítimos - ou ilegítimos, no ponto de vista moderno. A cada interação entre um saber local e o saber suposto global, porém local, ambos se misturam, nunca ocasionando uma simples homogeneização, mas sim novas articulações de poder/saber. Cada local interage, a partir de suas particularidades, com esse conhecimento que se quer total, isto é, abstraído de seu local. Diversas são as "fórmulas" produzidas por essa "reação química” que devem ser estudadas- não a partir de um simples protecionismo local que as evite e encontre no 
isolamento, nas fronteiras rígidas, a sólida Verdade- mas sim a partir de uma visão que nunca se cristalize, que se coloque sempre tensionada e, por isso, em constante fluxo.

Desenvolvimento, partindo dessa concepção, passa a ser um terreno movediço, uma constante mutação de saberes/poderes, de conhecimento/política, sem uma referência que unifique o caminhar. Ele não deve ser pensado a partir de um saber cego que se quer Verdade, exterior ao local, fazendo com que este passe a gravitar em torno de sua cartilha. Por outro lado, desenvolvimento também não é fechar as fronteiras à ciência, ao suposto global, ao diferente, como se esses fossem um "mal essencial” e, por isso, devendo ser evitados a qualquer custo. Parece-me que, para se trilhar dentro do conceito de desenvolvimento, precisamos abrir mão das certezas, dos portos seguros e, dessa forma, flexibilizar tudo aquilo que se enrijeceu. Devemos povoar as interfaces dessas redes. Um local deve interagir com outros locais - entre eles o suposto global - sempre no sentido de um desenvolvimento que já não mais possui um fundamento rígido - como assim o queria os defensores dos modelos desenvolvimentistas clássicos e dos mais atuais.

Penso poder haver um diálogo entre os diversos saberes, entre as diferenças, e uma visão que se recuse a enxergar através das antigas dicotomias. A noção de desenvolvimento passa por termos um olhar simétrico para as diversas culturas, inclusive a ocidental moderna, examinando

“a produção de saberes sem precisar, por sua vez, classificá-los em selvagem e doméstico, mito ou racional, moderno ou tradicional, lógico ou ilógico” (Latour, 1999: 176).

Ver oposições, significa transformar ambos os lados em sólidos incomunicáveis entre si. O desenvolvimento, dessa maneira, estaria na busca de uma pureza unilateral, e não em um diálogo, um processo de tradução entre diferentes. As redes de natureza/cultura, propostas por Latour, não são redes da Verdade, mas de verdade, sempre parciais e históricas, nunca totais e atemporais. Pensar em desenvolvimento a partir do conceito de redes não significa dizer que "tudo é relativo e, portanto, estanque, cada um devendo ficar no seu canto seguindo seus respectivos passos”. Significa respeitar a legitimidade de todo saber, sem perder de vista a interação inevitável entre diferentes. Significa povoar as interfaces sabendo que elas não são o limite entre o Verdadeiro e o Falso.

Penso ser nos limites das redes que surge a possibilidade do desenvolvimento, do surgimento do novo que inclui uma nova amarra no emaranhado da rede e reverberando nessa de forma imprevisível. Cada amarra "fala” da rede inteira à sua maneira. As redes se expandem de diferentes maneiras em cada amarra, em cada local. O desenvolvimento se situa em cada nova amarração, em cada interface entre diferentes redes. Quanto ao modelo de desenvolvimento a ser proposto, não existe aquele que pode ser considerado " $A$ " referência (Maciel, 1998). A interação será sempre uma comunicação entre diferentes saberes coletivos, amarras em redes de trabalho que envolve humanos e não-humanos, que poderão vir a formar novos saberes. As redes 
"podem ser comparadas em função de seus tamanhos, dos números de pontos ligados, do volume de trocas, mas não podem ser classificadas em função de sua maior ou menor lógica ou verdade”(Latour, 1999: 177).

Desenvolvimento então, parece ser uma interação entre diferentes, onde ambos os lados tem status simétrico e, por isso podem se comunicar.

\section{Referências}

- BAUMAN, Z. Modernidade e ambivalência. Rio de Janeiro: Jorge Zahar, 1999.

- FOUCAULT, M. Microfísica do Poder. 14. ${ }^{\circ}$ Edição. Rio de Janeiro: Ed. Graal, 1999.

- KUHN, T. S. A estrutura das revoluções científicas. 5. Edição. São Paulo: Perspectiva, 2000

- LATOUR, B. Jamais fomos modernos. São Paulo: Ed. 34, 1994.

• C Como redividir a grande divisão. Mosaico - Revista de Ciências Sociais, 2(1): 168-199, 1999.

- MACIEL, M. de F. Contribuições da Ecologia Humana para a Psicologia Social Moderna:

Perspectivas para uma Ecologia Social. Arquivos Brasileiros de Psicologia. Rio de Janeiro:

No. 8. pp. 22-31, 1998.

- MORIN, E. \& Kern, A. B. Terra-Pátria. 2. Edição. Porto Alegre: Sulina, 1995.

- SANTOS, M. Por uma outra Globalização: do pensamento único à consciência universal.

5. ${ }^{\circ}$ edição. Rio de Janeiro: Record, 2001.

- PRIGOGINE, I. \& STENGERS, I. A nova aliança. Brasília: Ed. UNB, 1991.

\section{Informações bibliográficas:}

Conforme a NBR 6023:2002 da Associação Brasileira de Normas Técnicas (ABNT), este texto científico publicado em periódico eletrônico deve ser citado da seguinte forma:

NOBRE, J. C. A.. Problematizando o Conceito de Desenvolvimento: povoando as interfaces. Cadernos UniFOA, Volta Redonda, ano 2, nº. 3, mar. 2007. Disponível em: $<$ http://www.unifoa.edu.br/pesquisa/caderno/edicao/03/54.pdf> 